\title{
Shifting Control Algorithm for a Single-Axle Parallel Plug-In Hybrid Electric Bus Equipped with EMT
}

\author{
Yunyun Yang, Sen Wu, and Xiang Fu \\ Hubei Key Laboratory of Advanced Technology of Automobile Parts, School of Automotive Engineering, \\ Wuhan University of Technology, Wuhan 430070, China
}

Correspondence should be addressed to Yunyun Yang; kristyyueng@163.com

Received 23 September 2014; Accepted 24 November 2014; Published 21 December 2014

Academic Editor: Muhammad Naveed Iqbal

Copyright (c) 2014 Yunyun Yang et al. This is an open access article distributed under the Creative Commons Attribution License, which permits unrestricted use, distribution, and reproduction in any medium, provided the original work is properly cited.

Combining the characteristics of motor with fast response speed, an electric-drive automated mechanical transmission (EMT) is proposed as a novel type of transmission in this paper. Replacing the friction synchronization shifting of automated manual transmission (AMT) in HEVs, the EMT can achieve active synchronization of speed shifting. The dynamic model of a single-axle parallel PHEV equipped with the EMT is built up, and the dynamic properties of the gearshift process are also described. In addition, the control algorithm is developed to improve the shifting quality of the PHEV equipped with the EMT in all its evaluation indexes. The key techniques of changing the driving force gradient in preshifting and shifting compensation phases as well as of predicting the meshing speed in the gear meshing phase are also proposed. Results of simulation, bench test, and real road test demonstrate that the proposed control algorithm can reduce the gearshift jerk and the power interruption time noticeably.

\section{Introduction}

In the past few years, hybrid electric vehicles (HEVs) have demonstrated advantages in reducing the fuel consumption and pollution emissions [1-3]. Compared with conventional HEVs, plug-in hybrid electric vehicles (PHEVs) can recharge from an external source. Before the technology of pure electric vehicles (EV) becomes mature, PHEVs offer a feasible solution to the transportation in which part of the required petroleum resource is replaced with electricity [4].

The driveline system plays a crucial role in vehicle's fuelsaving performance and driving comfort. Automated manual transmission (AMT) has been a decent candidate for the power transmission of heavy HEVs for its high efficiency, low cost, and high reliability. Besides, AMT can be modified in the conventional transmissions. However, AMT has still some drawbacks of power interruption and shifting jerk in the gear shifting process. Furthermore, the excessive wears of the clutch disc and synchronizer affect the application of AMT in HEVs [5-7]. Much research has been conducted to find better solutions to AMTs' shortcomings in HEVs. For reducing the power interruption time, Baraszu and Cikanek [8] proposed that the vehicles should be directly driven by motor during the gear shifting process in parallel HEVs equipped with AMT. Jo et al. [9] and Liao et al. [10] introduced a control strategy which controlled the torques and speeds of the engine and motor to reduce the synchronizing torque of AMTs' synchronizer and clutch. So far few literatures on the gear shifting control strategies without disengaging the clutch for HEV s equipped with AMT have been reported [5, 11, 12]. But those disadvantages of AMT could not be thoroughly avoided due to the slow response of engine.

In order to solve these problems, we designed a new automatic transmission, namely, electric-drive automated mechanical transmission (EMT), which improved the structure of AMT. By removing the synchronizer of AMT and adding the drive motor and the control system to it, the EMT was constructed. With the rapid response of the motor, it could control the speed and torque of the motor to achieve shifting synchronization in gear shifting process. Thus the acceleration steadiness and the degree of smoothness of the vehicle are achieved [13-17], and consequently the vehicle drivability is improved.

In this paper, a gear shifting control algorithm is designed for a single-axle parallel PHEV equipped with EMT. To do this, the dynamic properties of the gearshift process are 


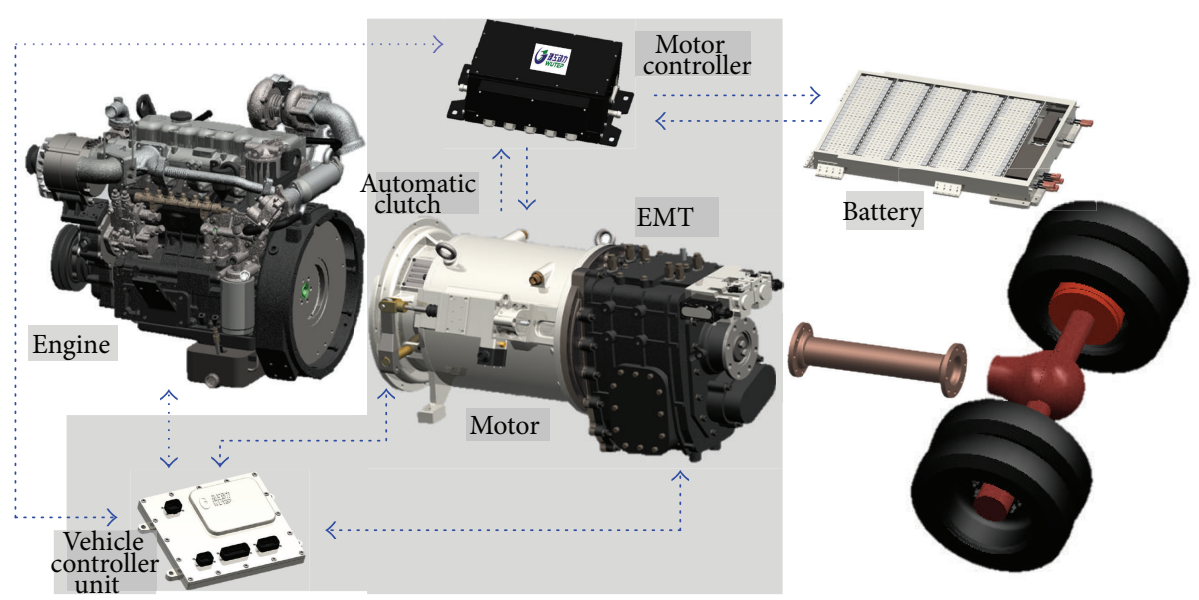

FIGURE 1: Structure diagram of a parallel PHEB powertrain with EMT.

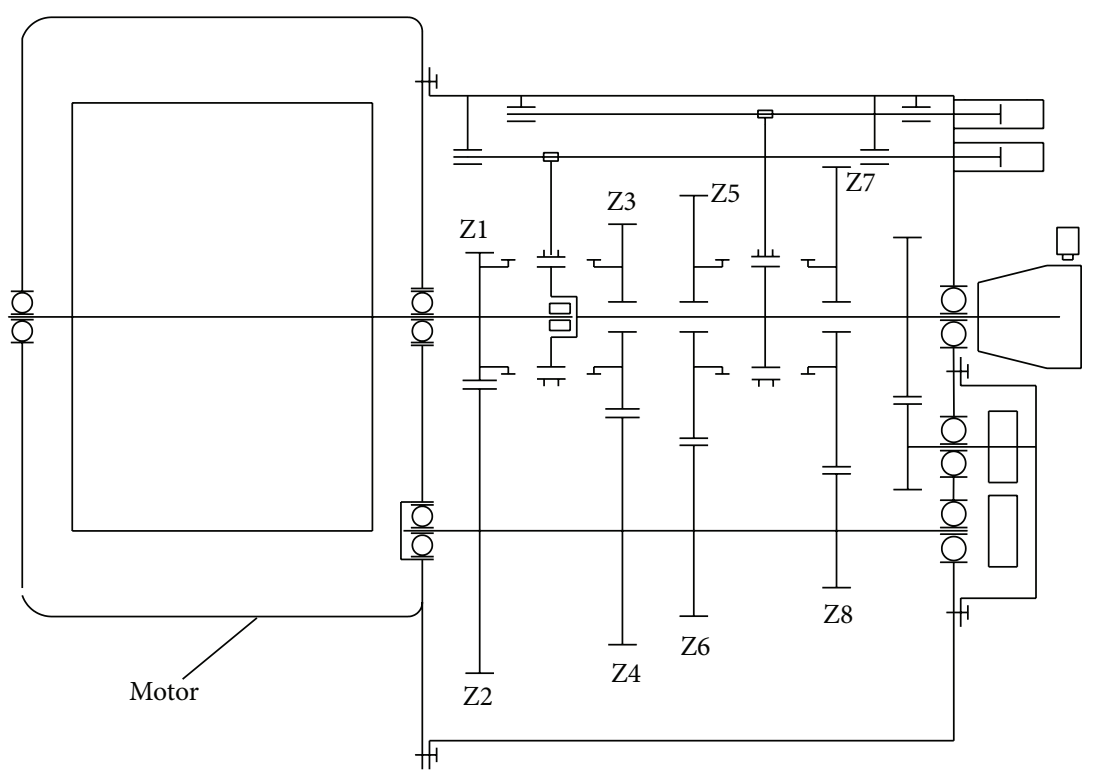

FIgUre 2: Configuration of the four-gear EMT.

discussed, and then the dynamic model of the powertrain system is built up. The EMT is integrated to a plug-in hybrid electric bus (PHEB). To study the effectiveness of the proposed gearshift control algorithm, the bench test and real road test are performed. The results of the simulation and tests prove that the presented control algorithm can obtain an outstanding gear shifting quality.

\section{The Architecture and Working Principle of the EMT in Single-Axle Parallel PHEB}

The powertrain system configuration of the single-axle parallel PHEB with EMT is shown in Figure 1. In electric mode the clutch is disengaged, while in other modes the clutch is engaged. Those components including the engine, the EMT, the clutch, and the electrical controller are all controlled by the vehicle control unit (VCU). The EMT without reverse gear has several forward gears and the vehicle can achieve reversing by the motor rotating reversely.

The configuration of a 4-gear EMT proposed in this paper is depicted in Figure 2. As shown in Figure 2, the EMT is composed of a motor, a mechanical transmission with three shafts, and a shift actuator. Instead of the synchronizer in traditional transmission, the EMT uses the gear clutch teeth to mesh and separate in the gear shifting process, which is helpful for reducing the axial size. In gear shifting process, the EMT can shift to the target gear by adjusting the speed of the transmission input shaft (also the motor shaft) during the speed synchronization phase.

The gear shifting process of the PHEV with EMT is shown in Figure 3. The schematic diagram displays the vehicle starting with the 2nd gear and upshifting to the 4 th gear continuously. When the vehicle starts, the engine is in an idle state and the clutch is disengaged; the EMT shifts to 


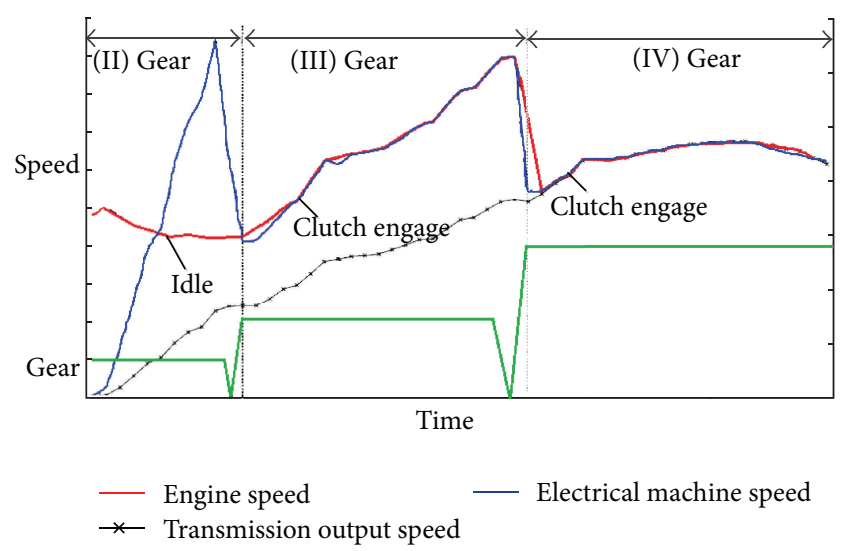

FIGURE 3: Gear shifting process of the PHEV with EMT.

the 2nd gear; and the vehicle runs in a pure electric mode. As the motor speed increases to the upshift point, the EMT switches to the 3rd gear. After gear shifting, the vehicle still runs in the electric mode; when the engine and the motor are controlled to have the same rotating speed, the clutch is engaged. The vehicle is driven solely by the motor during the whole clutch engagement process. After the clutch is engaged, the vehicle switches to the hybrid mode (decided by the whole vehicle energy management strategy). When the speeds of the engine and the motor increase to the 3rd upshift point, the clutch is separated and the transmission shifts off to the neutral gear, and then the EMT starts to switch to the 4th gear, which shares the same principle with the shift from the 2 nd gear to the 3 rd gear.

\section{Gear Shifting Quality Evaluation Indexes}

The gear shifting quality evaluation indexes of the PHEV with EMT are power interruption time, shifting jerk $[18,19]$, and the service life of the shifting components.

3.1. Power Interruption Time. The power interruption time $t_{\mathrm{PI}}$ refers to the time when vehicle is decelerating in the gear shifting process, namely, the time when the acceleration is negative. The gear shifting time of the single-axle parallel $\mathrm{HEV}$ with EMT includes the time $t_{1}$ of disengaging the clutch, the time $t_{2}$ of shifting-off to the neutral gear, the time $t_{3}$ of motor active synchronization, and the time $t_{4}$ of shifting on the target gear. Then the equation of the power interruption time can be expressed as

$$
t_{\mathrm{PI}}=\max \left(t_{1}, t_{2}\right)+t_{3}+t_{4}
$$

3.2. Gear Shifting Jerk. The gear shifting jerk is the changing rate of the vehicle's acceleration [20, 21]; it significantly influences the drivability during the shifting process and can be represented as

$$
j=\frac{d a}{d t}=\frac{d}{d t}\left(\frac{d v}{d t}\right)
$$

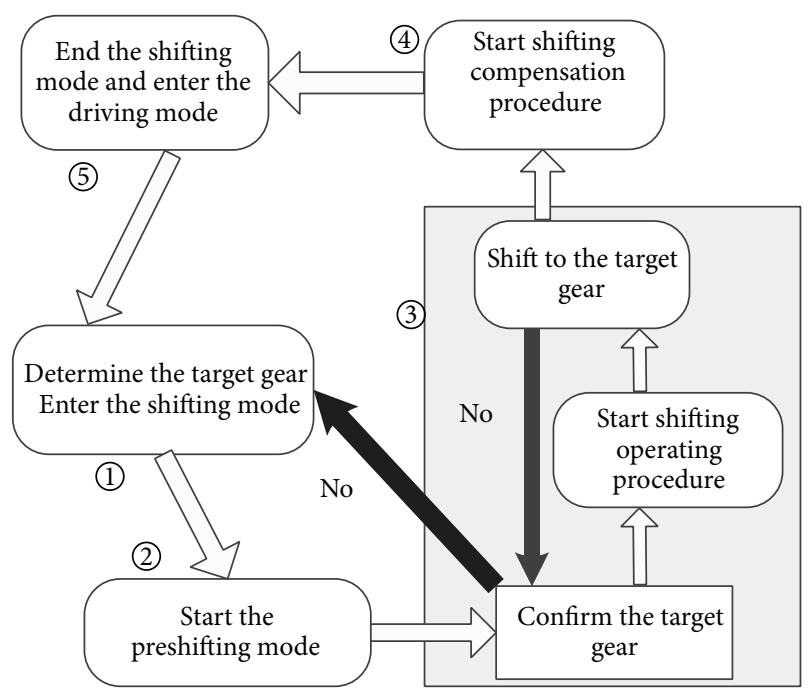

FIGURE 4: Flow diagram of the gearshift process for the PHEV equipped with EMT.

where $v$ is the vehicle velocity; $a$ is the vehicle longitudinal acceleration.

\section{Control Algorithm Analyses for EMT Shifting}

For obtaining excellent gear shifting quality, an optimal control algorithm is critical. When the vehicle is not in gear shifting process, the motor and engine are controlled by the VCU according to the vehicle control strategies and can be represented as follows:

$$
\begin{aligned}
& T_{e}=f\left(\alpha_{e}, n_{e}\right), \\
& T_{m}=T_{\text {req }}-T_{e},
\end{aligned}
$$

where $\alpha_{e}$ is the engine throttle opening, $n_{e}$ is the engine speed, $T_{\text {req }}$ is the vehicle demand torque, $T_{e}$ is the output torque of the engine, and $T_{m}$ is the output torque of the motor.

The gear shifting process of the single-axial parallel PHEV with EMT is shown in Figure 4. When the target gear is determined by the input conditions, the EMT switches to the shifting mode (step (1) in Figure 4). The process starts with the preshifting procedure (step (2) in Figure 4) determined by the torque request of the vehicle, which can make the vehicle transit to the shifting operating procedure smoothly. Then the EMT evaluates the target gear in real time according to the road condition and driver's physical conditionbecause the preshifting phase has no power interruption (step (3) in Figure 4). When the target gear is confirmed, the EMT switches to the gear shifting operation procedure (the key of gearshift process). After shifting to the target gear, the EMT starts the shifting compensation procedure (step (4) in Figure 4), which compensates the torque request for the vehicle. With the finish of the phase (4), the shifting mode ends and is followed by the driver operating mode (step (5) in Figure 4). In the synthesis, the gear shifting process in a single-axle parallel PHEV with EMT is divided into five 
processes, forming the whole power process of driving and shifting. The concrete analysis of the gear shifting processes (2) (3) (4) will be done below.

4.1. Preshifting Process. When the vehicle needs to shift to the new gear which is determined by the VCU, the powertrain switches to the shifting mode and starts the preshifting program. The system breaks off the shifting program only when the brake pedal is stamped by the driver. And then the system responds to the control strategies of the vehicle and gear shifting; otherwise the system switches to the shifting process smoothly. The main function of the preshifting program is to weaken the negative effects of the power interruption in the shifting process.

When the vehicle is running on a flat road, the driving force can be expressed as

$$
F_{t}=F_{f}+F_{w}+F_{j}
$$

where $F_{t}$ is the driving force, $F_{f}$ is the rolling resistance, $F_{w}$ is the air resistance, and $F_{j}$ is the acceleration resistance which is related to the acceleration. The equation of $F_{j}$ can be expressed as follows:

$$
F_{j}=\delta_{1} m \frac{d u}{d t}
$$

where $m$ is the gross vehicle weight and $\delta_{1}$ is the rotary mass coefficient of the vehicle in this process. The equation of the shifting jerk can be represented as

$$
j=\frac{d^{2} u}{d t^{2}}=\frac{d\left(F_{j} / \delta m\right)}{d t}=\frac{d\left(F_{t}-F_{f}-F_{w}\right)}{\delta m d t} .
$$

According to the shifting requirements, the shifting jerk must meet the following condition:

$$
j \leq j_{\max },
$$

where $j_{\max }$ is the reference value of the maximum gear shifting jerk. The recommended values are $31.63 \mathrm{~m} / \mathrm{s}^{3}$ in former Soviet Union and $10 \mathrm{~m} / \mathrm{s}^{3}$ in Germany.

To avoid the power interruption in the preshifting phase and to minimize the shifting jerk of the switching to neutral gear in the shifting process, the vehicle acceleration in the end of the preshifting phase should approach zero, and thus the equation can be written as follows:

$$
F_{w 1}+F_{f 1}-F_{t 1}=0
$$

where $F_{w 1}, F_{f 1}$, and $F_{t 1}$ are the air resistance, the rolling resistance, and the driving force in the end of the preshifting phase.

Then the equation of average jerk $j_{a}$ is

$$
\begin{aligned}
j_{a} & =\frac{\left(F_{t 1}-F_{w 1}-F_{f 1}\right)-\left(F_{t 0}-F_{w 0}-F_{f 0}\right)}{\delta_{1} m \Delta t_{01}} \\
& =\frac{F_{w 0}+F_{f 0}-F_{t 0}}{\delta_{1} m \Delta t_{01}} \leq j_{\max },
\end{aligned}
$$

where $F_{w 0}, F_{f 0}$, and $F_{t 0}$ are the air resistance, the rolling resistance, and the driving force in the beginning of the preshifting phase and $\Delta t_{01}$ is the time of the preshifting phase.

From (8) and (9), we can get

$$
\frac{F_{t 0}}{\Delta t_{01}} \geq \frac{F_{w 0}+F_{f 0}}{\Delta t_{01}}-\delta_{1} m j_{\max } .
$$

The shifting jerk of the preshifting process can be ensured to meet (7) by controlling the driving force gradient $\left(d F_{t} / d t\right)$ with the following requirement:

$$
\frac{d F_{t}}{d t} \geq \frac{F_{w 0}+F_{f 0}}{\Delta t_{01}}-\delta_{1} m j_{\max }
$$

In the preshifting phase, the output torque of the power source (decided by the vehicle control strategies) is controlled by the control strategy of the driving force gradient.

4.2. Shifting Operation Process. The shifting operation process has three phases: shifting-off phase, motor active speed synchronization phase, and shifting compensation phase. The following actions will be performed to realize the shifting.

(a) Disengage the clutch in the shortest time according to the indexes of the shifting jerk and the power interruption time; meanwhile, the motor switches to the idle mode with no torque output and the engine switches to the idle mode. Then the transmission switches to the neutral gear.

(b) In order to realize the speed synchronization of the input and output shafts, the motor adjusts the speed in torque control mode; meanwhile, the target speed of the motor is calculated.

(c) The transmission switches to the target gear when it meets the shifting requirements.

4.2.1. Shifting-Off Phase. In this phase, the clutch starts to separate and the transmission switches to the neutral gear. The average jerk of this phase can be represented as

$$
j_{a 1}=\frac{\left(\left(F_{t 2}-F_{w 2}-F_{f 2} / \delta_{2} m\right)-\left(F_{t 1}-F_{w 1}-F_{f 1} / \delta_{1} m\right)\right)}{\Delta t_{12}}
$$

where $F_{w 2}, F_{f 2}$, and $F_{t 2}$ are the air resistance, the rolling resistance, and the driving force in the end of the shiftingoff phase, $\Delta t_{12}$ is the time of the shifting-off phase, and $j_{a 1}$ is the average jerk of this phase.

In the gearshift process, we may consider that the vehicle acceleration is approximately equal to zero, so it is easy to shift off without excessive wear on the gears surfaces. Then the rolling resistance and the air resistance keep unchanged. The average jerk can also be represented as

$$
j_{a 1}=\frac{-\left(F_{w 2}+F_{f 2}\right)}{\delta_{2} m \Delta t_{12}}=\frac{-\left(F_{w 1}+F_{f 1}\right)}{\delta_{1} m \Delta t_{12}}=\frac{-\left(F_{w 0}+F_{f 0}\right)}{\delta_{1} m \Delta t_{12}} .
$$



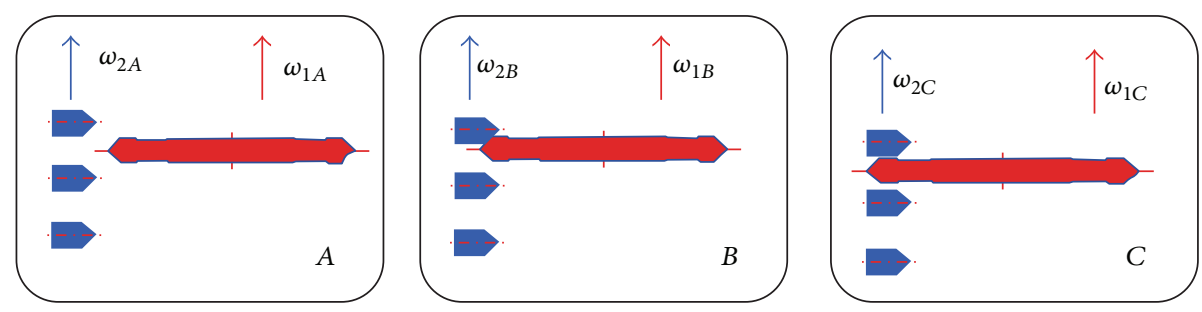

FIGURE 5: The movement positions of the shift sleeve in shifting process.

4.2.2. Motor Active Speed Synchronization Phase. After switching to the neutral gear, start to reduce the speed difference between the shift sleeve and shift gear of the target gear, which is called motor active speed synchronization phase.

The sketch of the movement positions of the shift sleeve teeth in shifting process is shown in Figure 5. The red teeth represent the teeth of the shift sleeve while the blue ones represent those ofthe shift gear. $A$ stands for the end of the active synchronization phase and $B$ stands for the beginning of the gear meshing; $C$ stands for the end of the gear meshing; $\omega_{1 A}, \omega_{1 B}$, and $\omega_{1 C}$ represent the rotating speed of the shift sleeve in stages $A, B$, and $C$, respectively; $\omega_{2 A}, \omega_{2 B}$, and $\omega_{2 C}$ represent the speed of theshift gear in stages $A, B$, and $C$, respectively.

The speeds of the input shaft and the output shaft should be predicted in the process from $A$ to $B$, which is the idle motion process of the shift sleeve. The ideal condition of $B$ is

$$
\omega_{1 B}=\omega_{2 B} .
$$

In the active speed synchronization phase, the speed variation trends of the shift sleeve and shift gear should be predicted accurately. By theoretical analysis, this paper adopts the mean evaluation method to predict the target speed of the speed regulation. The equations of this phase are as follows:

$$
\begin{gathered}
\omega_{1 B}=\omega_{1 A}+a_{1} \cdot t_{A-B}, \\
\omega_{2 B}=\omega_{2 A}+a_{2} \cdot t_{A-B}, \\
\omega_{1 A}+a_{1} \cdot t_{A-B}=\omega_{2 A}+a_{2} \cdot t_{A-B},
\end{gathered}
$$

where $a_{1}$ is the acceleration of the shiftsleeve, $a_{2}$ is the acceleration of the gear shaft, and $t_{A-B}$ is the time from $A$ to B.

The speed of shift sleeveis measured by the speed sensor of the output shaft, while the speed of gear shaft is measured by the speed sensor of the motor; $a_{1}$ is calculated by the relationship between the speed of the output shaft and the speed regulation time. At the end of the active synchronization phase, the acceleration of the motor cannot be measured, so the acceleration of the gear shaft $a_{2}$ cannot be obtained either. Through numerous experiments, the value of $\omega_{2 B}$ can be predicted as follows:

$$
\omega_{2 A}+a_{2} \cdot t_{A-B}=k_{p} \cdot \omega_{2 A},
$$

where $k_{p}$ is the proportionality coefficient which is related to the speed and the output torque of the motor. In practical

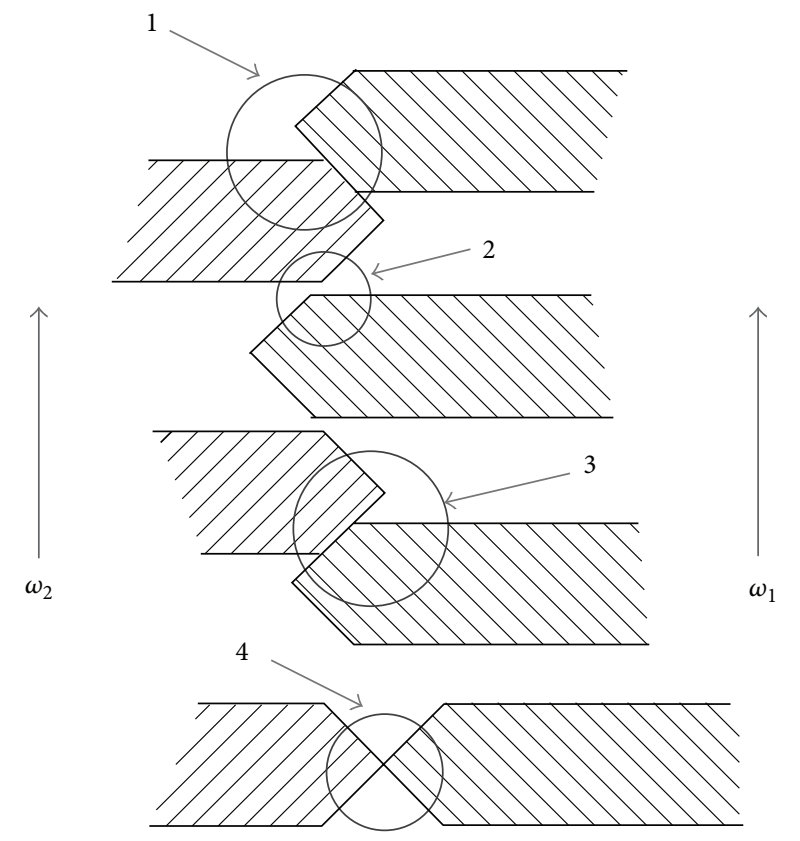

FIGURE 6: Position relationships between the teeth of shift sleeve and those of shift gear.

applications, the parameter compensations are added to the output shaft acceleration $a_{1}$ which is replaced with the weight value $\Sigma a_{1}$. The equation of the weight value $\Sigma a_{1}$ can be expressed as

$$
\Sigma a_{1}=k a_{1}+(1-k) a_{a}
$$

where $k$ is the weight coefficient which is related to the vehicle speed in the beginning of the active synchronization and $a_{a}$ is the average speed of shift sleeve in the active synchronization. Then $\omega_{2 A}$ can be controlled as the following equation:

$$
\omega_{2 A}=\frac{\left(\omega_{1 A}+\Sigma a_{1} \cdot t_{A-B}\right)}{k_{p}} .
$$

4.2.3. Gear Meshing Phase. In this phase, the teeth of shift sleeve and those of shift gear begin to mesh. As shown in Figure 6, there are four different position relationships between the teeth of shift sleeve and those of shift gear in the gear meshing phase. The stages 2 and 4 are both special situations, representing small probability events, while the stages 1 and 3 appear in most cases. Although the causes of 

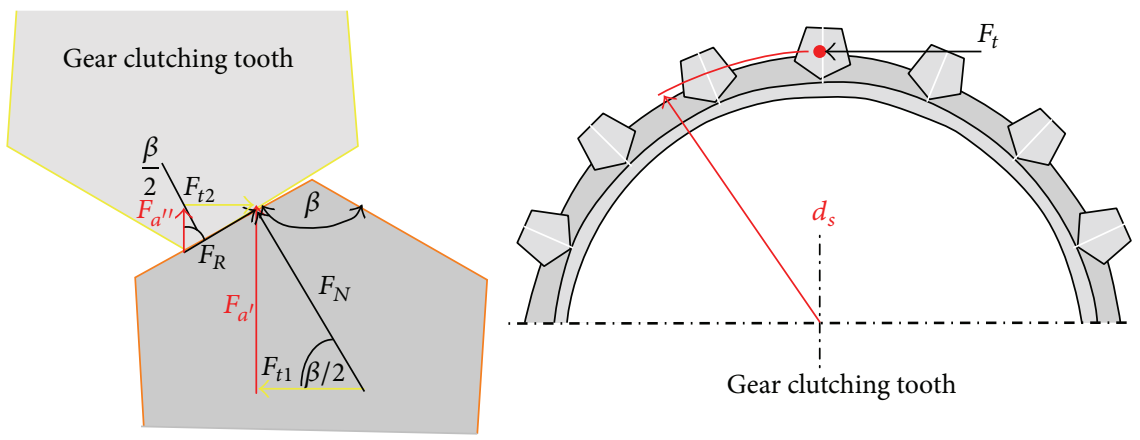

FIGURE 7: The acting forces applied on the tooth of shift sleeve and those on the shift gear.

stages 1 and 3 are different, they have the same force situation. Take stage 1, for example, to analyze the force of the meshing teeth at the contact moment.

The acting forces applied on the tooth of shift sleeve and those on the shift gear are shown in Figure 7. The equations of the forces can be expressed as follows:

$$
\begin{gathered}
M_{s}=F_{t} \times \frac{d_{s}}{2}, \\
F_{t}=F_{t 1}-F_{t 2}, \\
F_{R}=u_{s} \times F_{N}, \\
F_{a}=F_{a^{\prime \prime}}+F_{a^{\prime}}, \\
F_{t}=F_{N}\left(\cos \frac{\beta}{2}-u_{s} \times \sin \frac{\beta}{2}\right), \\
F_{a}=F_{N}\left(\sin \frac{\beta}{2}+u_{s} \times \cos \frac{\beta}{2}\right), \\
F_{N}=\frac{F_{a}}{\sin (\beta / 2)+u_{s} \times \cos (\beta / 2)}, \\
F_{t}=F_{a} \frac{\left(\cos (\beta / 2)-u_{s} \times \sin (\beta / 2)\right)}{\left(\sin (\beta / 2)+u_{s} \times \cos (\beta / 2)\right)} \\
M_{s}=F_{a} \times \frac{d s\left(\cos (\beta / 2)-u_{s} \times \sin (\beta / 2)\right)}{2\left(\sin (\beta / 2)+u_{s} \times \cos (\beta / 2)\right)}, \\
M \omega_{t}=\frac{d \omega_{2}}{d t},
\end{gathered}
$$

where $M_{s}$ is the blocking torque, $F_{t}$ is the tangential (along circumferential direction) force component, $F_{R}$ is the frictional force, $F_{N}$ is the normal force, $F_{a}$ is the axial shift force, $d_{a}$ is the mean effective diameter of the shift gear, $\beta$ is the angle of roof shape of the shift gear tooth, $u_{s}$ is the static friction coefficient of gear's meshing surface, $M_{k}$ is the moment of inertia, $J_{t}$ is the equivalent rotational inertia of jackshaft and the gears thereon, and $\omega_{2}$ is the rotational speed of the shift gear.
The axial force $F_{k}$ is generated by the moment of inertia $M_{k}$ which can be expressed as

$$
F_{k}=\frac{M_{k}}{d_{s} / 2} \cot \beta
$$

The teeth of shift sleeve and those of shift gear can mesh without failure when the following two conditions are satisfied: (1) $F_{k}<F_{a}$; (2) $M_{k}<M_{a}$.

To simplify the modeling, the static friction coefficient $u_{s}$ is assumed to be zero, so (27) can be simplified as follows:

$$
M_{s}=F_{a} \times \frac{d_{s}}{2} \cot \frac{\beta}{2} .
$$

As $M_{k}<M_{a}$, we can get

$$
F_{a}>\frac{J}{d_{s} / 2} \cdot \frac{d \omega}{d t} \tan \frac{\beta}{2}
$$

In this phase, the shifting jerk $j_{3}$ can be represented as

$$
j_{3}=\frac{d}{d t}\left(\frac{d u}{d t}\right)=\frac{d}{d t}\left(\frac{i_{0} \eta}{\delta_{3} m r} M_{k}\right)=\frac{i_{0} \eta}{\delta_{3} m r} \frac{d M_{k}}{d t} \leq j_{\max }
$$

where $m$ is the gross vehicle weight, $\delta_{3}$ is the rotary mass coefficient of the vehicle in the target gear, $\eta$ is the mechanical efficiency of transmission system, and $i_{0}$ is the main reduction ratio.

The maximum shifting jerk occurs at the moment when the teeth of shift gear contact those of the shift sleeve. According to (32), we know that the gear shifting jerk is connected with the change of the synthetic speed difference.

4.3. Shifting Compensation Phase. After shifting, the output torque of the motor is restored and the vehicle is driven by the motor. In this phase, the same control algorithm as that in the preshifting process is used to restore the output torque of the motor. The driving force gradient $\left(d F_{t} / d t\right)$ equation is expressed as

$$
\frac{d F_{t}}{d t}=\frac{F_{t 5}}{t_{45}} \leq j_{\max } \cdot \delta_{3} m,
$$




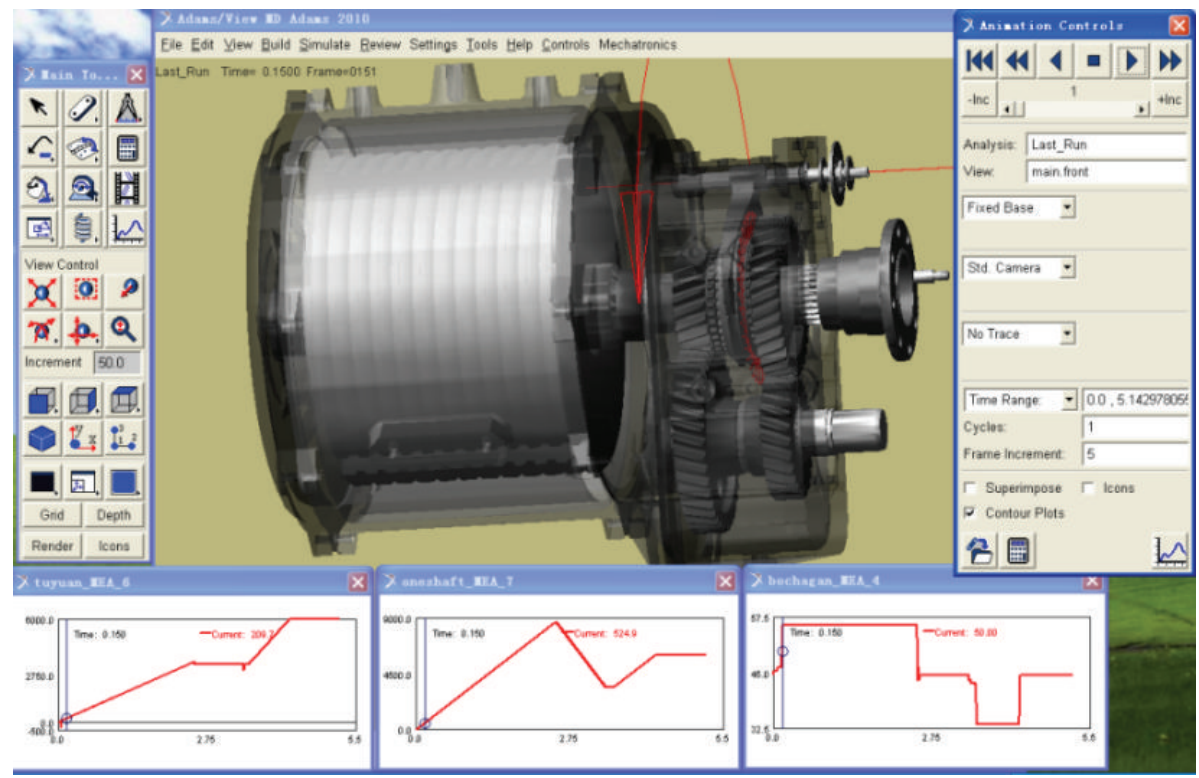

FIGURE 8: The EMT gear shifting process simulation.

TABLE 1: Simulation results of shifting quality with different motor torques.

\begin{tabular}{|c|c|c|c|c|c|}
\hline \multirow[t]{2}{*}{$\begin{array}{l}\text { Torque of the motor } \\
\text { speed adjustment/\% }\end{array}$} & $\begin{array}{l}\text { Shifting-off } \\
\text { time/ms }\end{array}$ & $\begin{array}{c}\text { Motor active } \\
\text { synchronization } \\
\text { time/ms }\end{array}$ & $\begin{array}{l}\text { Gear meshing } \\
\text { time } / \mathrm{ms}\end{array}$ & $\begin{array}{c}\text { Power interruption } \\
\text { time } / \mathrm{ms}\end{array}$ & Shifting jerk $/ \mathrm{m} / \mathrm{s}^{3}$ \\
\hline & $t_{2}$ & $t_{3}$ & $t_{4}$ & $t$ & $J$ \\
\hline 40 & 150 & 625 & 75 & 850 & 6.9 \\
\hline 60 & 150 & 400 & 75 & 625 & 7.8 \\
\hline 80 & 150 & 325 & 75 & 550 & 8.2 \\
\hline 100 & 150 & 250 & 75 & 475 & 9.6 \\
\hline 150 & 125 & 200 & 150 & 475 & 15.6 \\
\hline
\end{tabular}

where $F_{t 5}$ is the air resistance in the end of the shifting compensation phase and $\Delta t_{45}$ is the time of this phase.

In hybrid mode and engine mode, the clutch is engaged after this phase. Then the vehicle comes back to the driving mode which is controlled by the vehicle control strategies.

\section{Simulation Analysis}

The gear shifting process of the hybrid electric drivetrain system is a sophisticated multi-rigid-body control system with complicated physical properties. So it is difficult to get the accurate shifting performance. Then let us analyze the control algorithm proposed above with the virtual prototype technology. The EMT model is simulated on the software ADAMS (Automatic Dynamic Analysis of Mechanical Systems). For simplifying the simulation model, the 4-speed EMT is replaced with a 2-speed EMT mode as shown in Figure 8.

The simulation results of the speed and the shifting fork displacement response in the upshift process are shown in Figure 9. The EMT shifting control algorithm can satisfactorily meet the gearshift requirements. In the process of shifting from the 1st to the 2nd gear and when the speed of the input

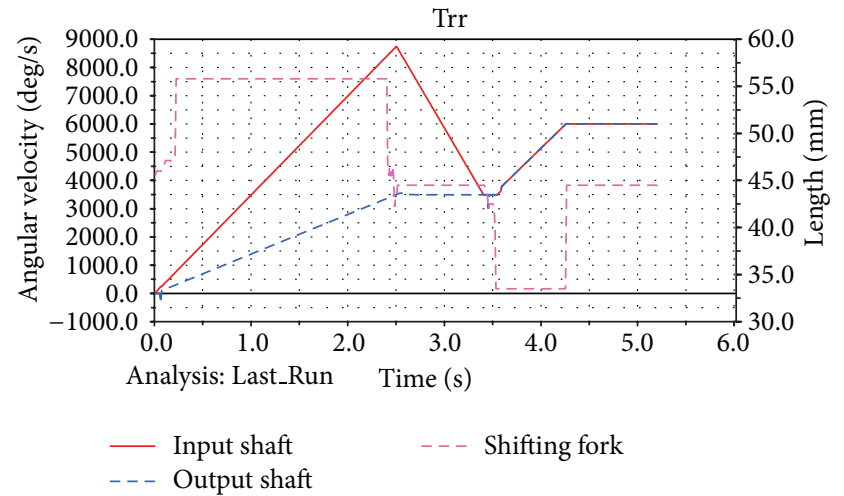

FIGURE 9: Simulation results of EMT shifting process.

shaft is adjusted to approach the output shaft speed, the shifting fork starts moving, and the transmission shifts to the 2nd gear. During the whole gear shifting process, the speed fluctuation of each shaft is small and so is the shifting jerk.

By optimizing the simulation parameters, we can get various shifting results of different motor torques in speed synchronization phase, as shown in Table 1; the sampling 


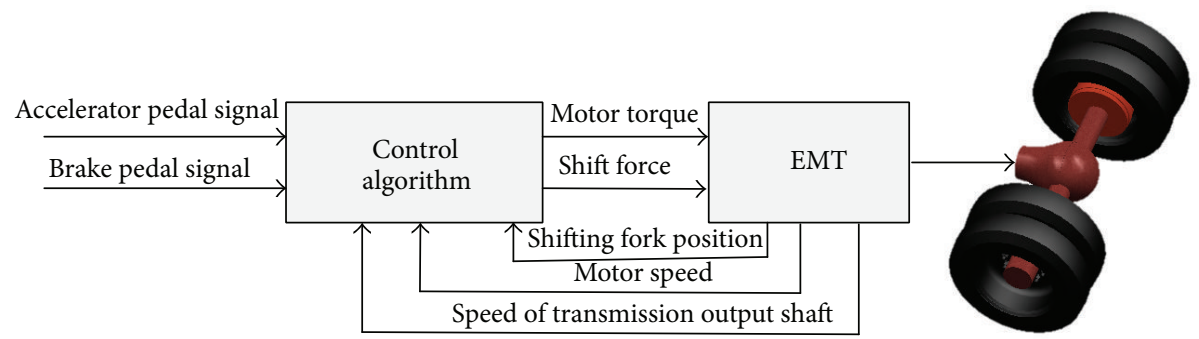

FIGURE 10: The diagram of the shifting process control model.

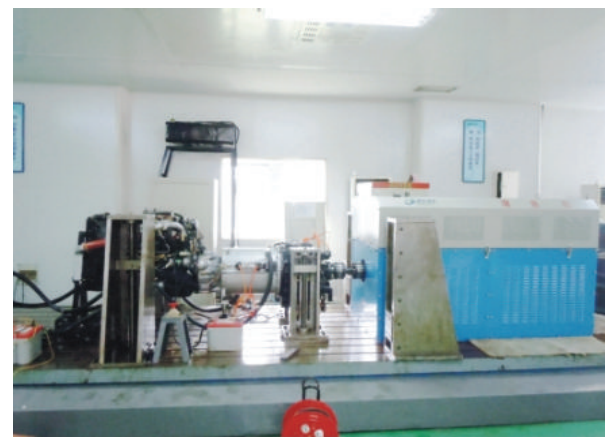

FIGURE 11: The test bench.

frequency is $25 \mathrm{~ms}$. The power interruption time is no more than $0.85 \mathrm{~s}$. We can also notice that the greater the torque of the motor regulating speed is, the shorter the power interrupt time is; and also the shorter the power interrupt time is, the greater the shifting jerk will be. When the torque of the regulating speed is below the $100 \%$, the power interruption time reduces with the increase of it, while when the torque of the regulating speed is over $100 \%$, the power interruption time change is small. This is due to the fact that, with the increase of the torque of the motor speed adjustment, the gear meshing time is longer despite the fact that the shiftingoff time and motor active synchronization time are shorter. According to the simulation results, we also know that, with the shifting control algorithm, the shifting jerk has been decreased and the shifting quality has been improved.

\section{Bench Test and Road Test}

To verify the control algorithm for shifting a single-axle parallel PHEB equipped with EMT, the bench test and road test were conducted, respectively. The vehicle parameters are shown in Table 2. The shifting process control model is shown in Figure 10. The test bench picture is shown in Figure 11.

The control system of the dynamometer can display the output torque and speed of power sources in real time, and the shifting jerk of output shaft can be calculated simultaneously. The test results of the continuous upshift and downshift processes performed with the EMT in the bench test are shown in Figure 12. For analyzing the control algorithm, the test results of the output shaft speed and the input shaft speed are shown in Figure 13 with marks. As shown in Figure 13, the
TABLE 2: The powertrain and vehicle parameters of the PHEB.

\begin{tabular}{lc}
\hline Parameters & Value \\
\hline Curb weight/full load gross mass/kg & $13000 / 18000$ \\
Main reducer ratio & 6.2 \\
Transmission ration (4-gear) & $5.82 ; 3.23 ; 1.79 ; 1$ \\
\hline Engine displacement/L & 2.98 \\
Maximum power $(\mathrm{kW}) /$ speed $(\mathrm{rpm})$ & $95 / 3200$ \\
Maximum torque $(\mathrm{Nm}) /$ speed $(\mathrm{rpm})$ & $345 / 1600 \sim 2400$ \\
\hline Motor & Induction motor \\
Rated/peak power $(\mathrm{kW})$ & $80 / 160$ \\
Maximum torque $(\mathrm{N} \cdot \mathrm{m})$ & 954 \\
\hline Lithium ion battery & $160 / 576$ \\
Capacitor $($ Ah)/rated voltage $(\mathrm{V})$ & \\
\hline
\end{tabular}

TABLE 3: The statistical data of the gearshift quality.

\begin{tabular}{lccccc}
\hline Gear change & $t_{2} / \mathrm{s}$ & $t_{3} / \mathrm{s}$ & $t_{4} / \mathrm{s}$ & $t_{\mathrm{PI}} / \mathrm{s}$ & $\begin{array}{c}\text { Maximum } \\
\text { shifting jerk } \\
\mathrm{m} / \mathrm{s}^{3}\end{array}$ \\
\hline $1 \rightarrow 2$ & 0.12 & 0.53 & 0.11 & 0.76 & 5.2 \\
$2 \rightarrow 3$ & 0.10 & 0.61 & 0.10 & 0.81 & 8.1 \\
$3 \rightarrow 4$ & 0.09 & 0.64 & 0.12 & 0.85 & 8.6 \\
$4 \rightarrow 3$ & 0.09 & 0.46 & 0.10 & 0.65 & -3.9 \\
$3 \rightarrow 2$ & 0.09 & 0.50 & 0.14 & 0.73 & -3.2 \\
$2 \rightarrow 1$ & 0.10 & 0.45 & 0.13 & 0.68 & -4.7 \\
\hline
\end{tabular}

phases of BC (1st to 2nd), DE (2nd to 3rd), and FG (3rd to 4th) are the upshift processes, while those of IJ (4th to $3 \mathrm{rd}$ ), KL (3rd to 2 nd), and MN (2nd to 1st) are the downshift processes.

The bench test results of shifting jerk are shown in Figure 14. The results of power interrupting time and shifting jerk of each gear are shown in Table 3. As can be seen from the Table, the power interrupt time is controlled within $0.85 \mathrm{~s}$, and the shifting jerk is controlled within $8.6 \mathrm{~m} / \mathrm{s}^{3}$. The motor active synchronization phase takes about $70 \%$ of the power interrupt time, which is impacted by the torque of the motor speed adjustment.

After plenty of bench tests, the road tests with a $12 \mathrm{~m}$ PHEV equipped with the EMT were conducted. The picture of the PHEB is shown in Figure 15. According to the control strategies, the test results of the engine speed, gear position sensor signals, clutch position sensor signals, motor speed, 


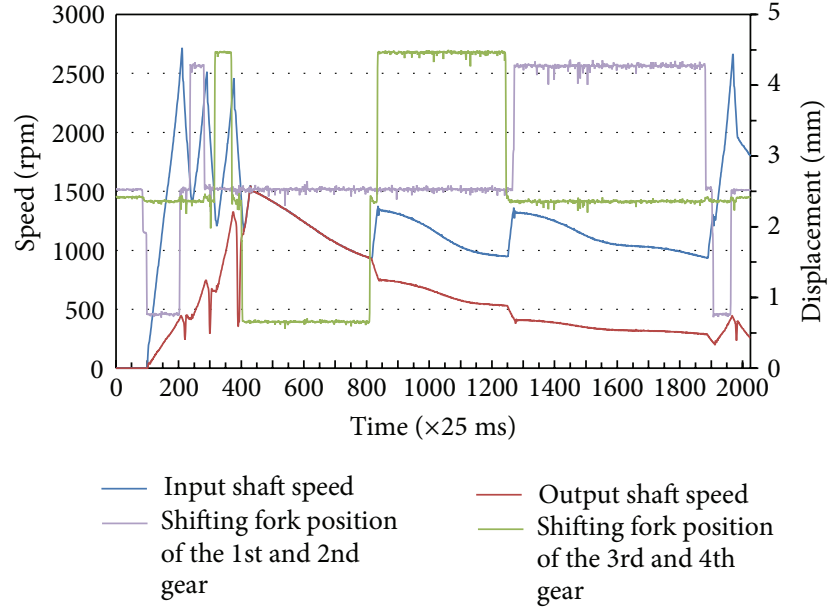

FIGURE 12: Test results of shifting process.

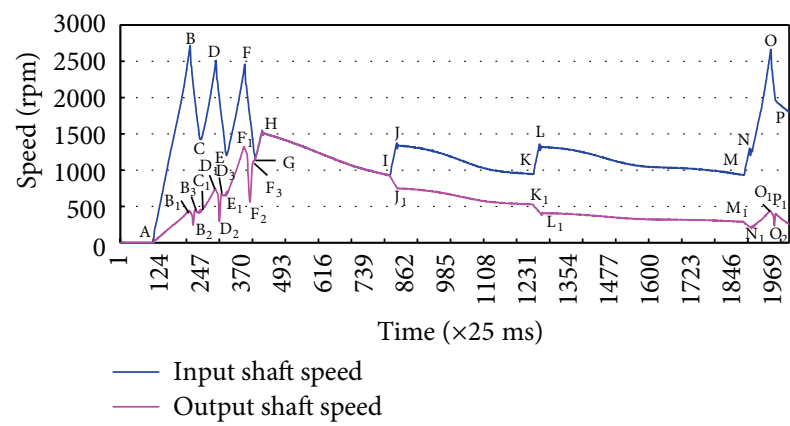

FIGURE 13: Test results of shifting with marks.

output shaft speed, and speed ratios are shown in Figure 16. The curves show the test processes in which the PHEB was starting with the 2 nd gear and accelerating to the 4 th gear and then decelerating and downshifting to the 2 nd gear. The power interrupt time of the PHEB is less than $0.8 \mathrm{~s}$, and the speed of the output shaft changes smoothly. The shifting jerk is no more than $10 \mathrm{~m} / \mathrm{s}^{3}$ which meets the recommended reference value of the shifting jerk in Germany.

\section{Conclusions}

In this paper, the working principle of a single-axle parallel PHEV equipped with an EMT is described, and analysis of the shifting dynamics model in each transient process is also given in detail. Moreover, a new shifting control algorithm is introduced for improving the gearshift quality without synchronizer. With the control algorithm, the gears of the single-axle parallel PHEV equipped with the EMT can be controlled to engage faster and successfully without excessive wear on the gear surfaces. It is also important to note that the control algorithm was verified on a simulation platform by the bench test and PHEB test. All the results prove that adopting this control algorithm in parallel PHEV equipped with the EMT can improve the shifting quality significantly
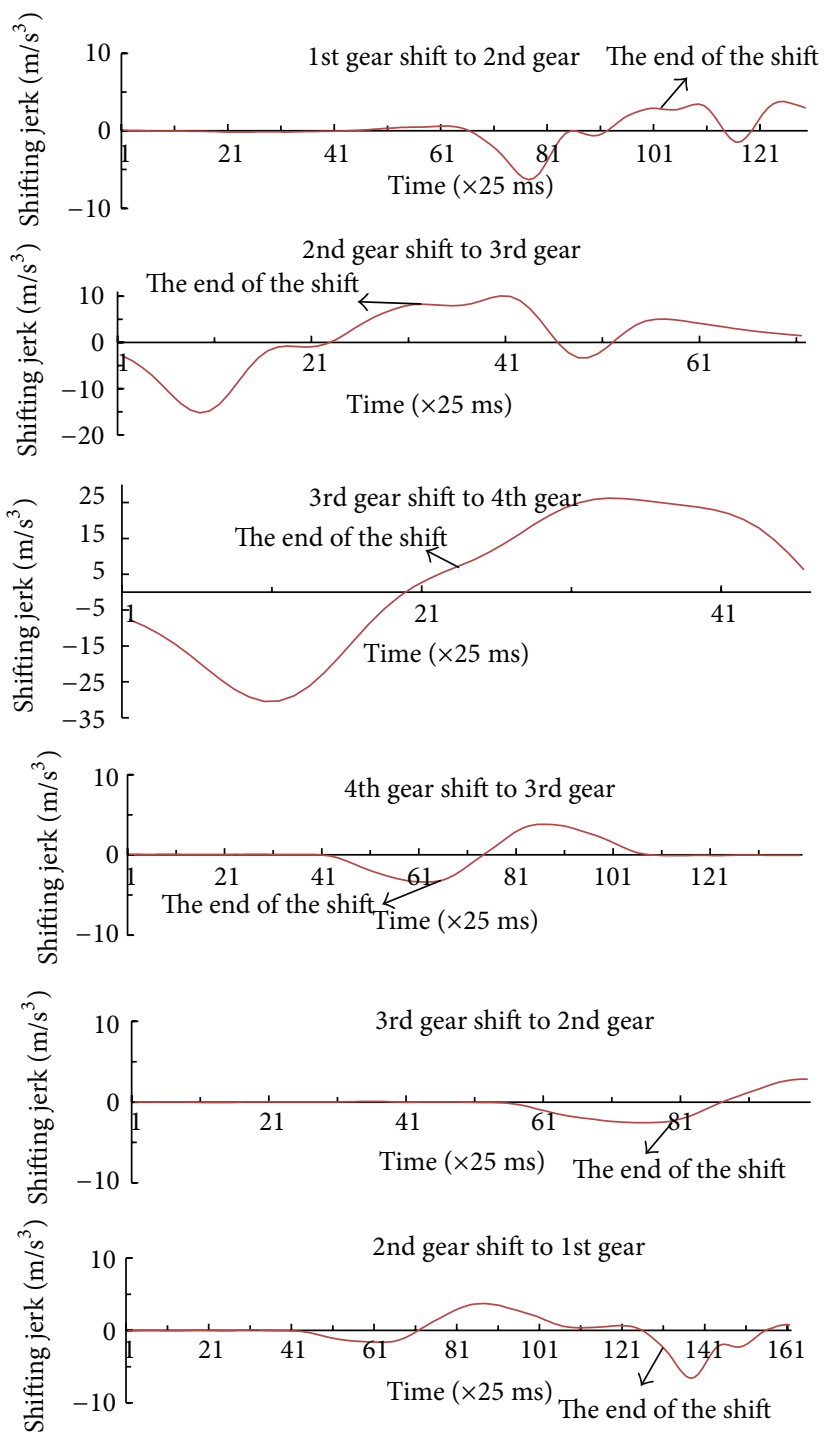

FIGURE 14: The test results of shifting jerk.

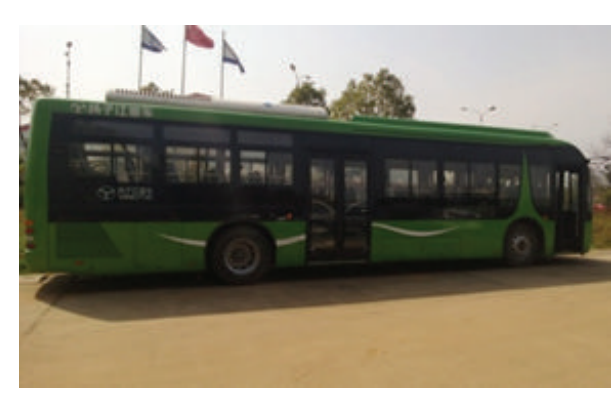

Figure 15: The test PHEB with EMT.

through its evaluation indexes, which is likely to help to replace the traditional AMT in HEV.

The EMT with proposed shifting control algorithm can also be applied to EVs and other kinds of HEVs to improve the shifting quality. In the near future, further study on EMT 


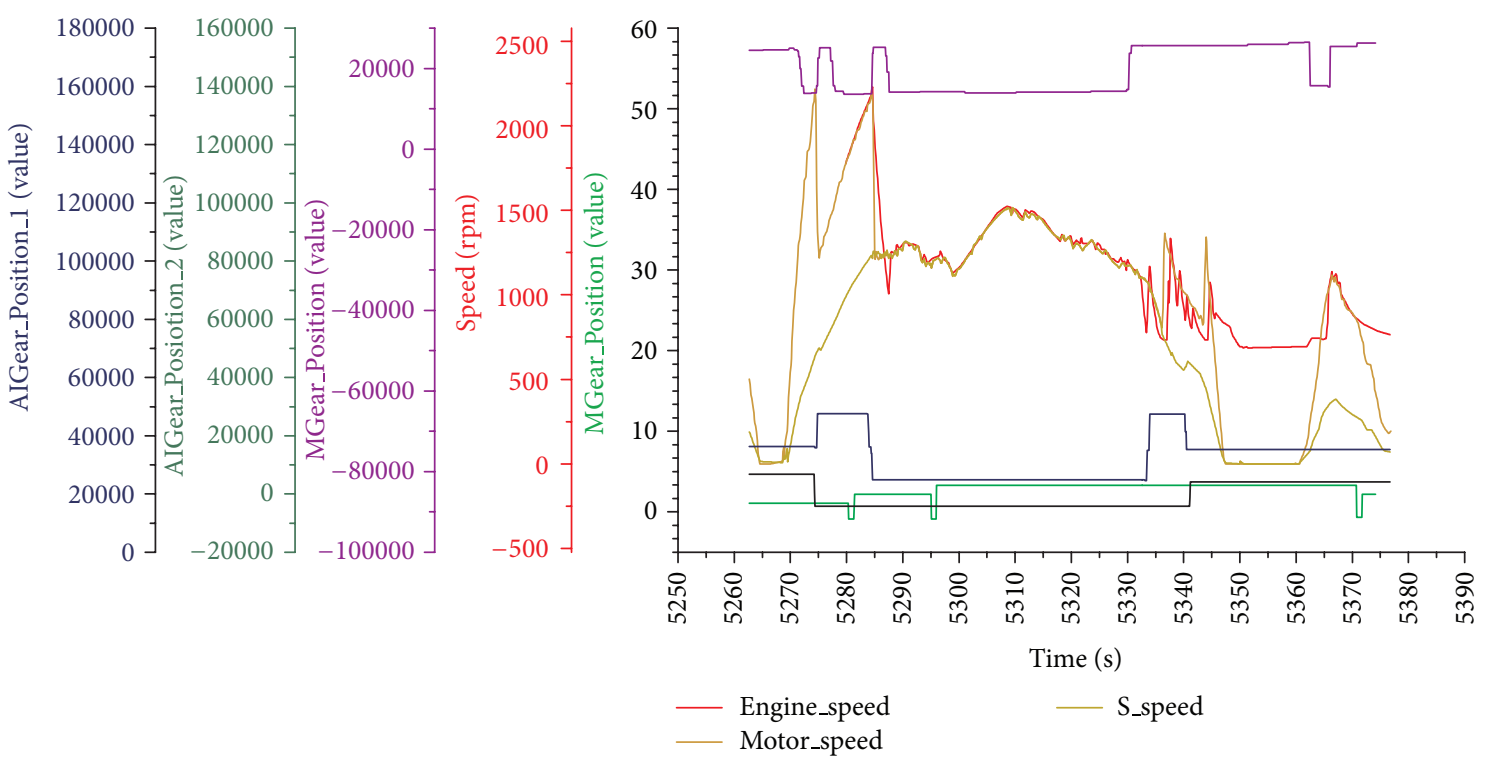

FIGURE 16: Road test curves of the gear shifting.

shifting will be carried on, and the new shifting algorithm will be proposed to improve the shifting quality further.

\section{Conflict of Interests}

The authors declare that there is no conflict of interests regarding the publication of this paper.

\section{Acknowledgment}

This work was supported by the National High Technology Research and Development Program of China (Grant no. 2011AA11A260).

\section{References}

[1] I. M. C. Uygan, A. E. Hartavi, L. Güvenç, V. Sezer, and T. Acarman, "Propulsion system design of a hybrid electric vehicle," International Journal of Vehicle Design, vol. 52, no. 14, pp. 96-118, 2010.

[2] T. Sousa, H. Morais, Z. Vale, P. Faria, and J. Soares, "Intelligent energy resource management considering vehicle-to-grid: a simulated annealing approach," IEEE Transactions on Smart Grid, vol. 3, no. 1, pp. 535-542, 2012.

[3] A. Y. Saber and G. K. Venayagamoorthy, "Plug-in vehicles and renewable energy sources for cost and emission reductions," IEEE Transactions on Industrial Electronics, vol. 58, no. 4, pp. 1229-1238, 2011.

[4] J. Tollefson, "Car industry: charging up the future," Nature, vol. 456, pp. 436-440, 2008.

[5] Z. Zhong, G. Kong, Z. Yu, X. Xin, and X. Chen, "Shifting control of an automated mechanical transmission without using the clutch," International Journal of Automotive Technology, vol. 13, no. 3, pp. 487-496, 2012.

[6] H. Yu, J. Xi, F. Zhang, and Y. Hu, "Research on gear shifting process without disengaging clutch for a parallel hybrid electric vehicle equipped with AMT," Mathematical Problems in Engineering, vol. 2014, Article ID 985652, 12 pages, 2014.

[7] L. Glielmo, L. Iannelli, V. Vacca, and F. Vasca, "Gearshift control for automated manual transmissions," IEEE/ASME Transactions on Mechatronics, vol. 11, no. 1, pp. 17-26, 2006.

[8] R. C. Baraszu and S. R. Cikanek, "Torque fill-in for an automated shift manual transmission in a parallel hybrid electric vehicle," in Proceedings of the American Control Conference, pp. 1431-1436, Anchorage, Alaska, USA, May 2002.

[9] H.-S. Jo, Y.-I. Park, J.-M. Lee, H.-D. Lee, and S.-K. Sul, "Development of an advanced shift control algorithm for a hybrid vehicles with automated manual transmission," Heavy Vehicle Systems, vol. 7, no. 4, pp. 281-298, 2000.

[10] C. Liao, J. Zhang, and Q. Lu, "Coordinated powertrain control method for shifting process of automated mechanical transmission in the hybrid electric vehicle," Chinese Journal of Mechanical Engineering, vol. 41, no. 12, pp. 37-41, 2005.

[11] X. T. Lu and G. Z. Hou, "Introduction of the AMT control system structure and main foreign AMT products," Automobile Technology, vol. 5, pp. 19-22, 2004 (Chinese).

[12] H. He, Z. Liu, L. Zhu, and X. Liu, "Dynamic coordinated shifting control of automated mechanical transmissions without a clutch in a plug-in hybrid electric vehicle," Energies, vol. 5, no. 8, pp. 3094-3109, 2012.

[13] M. Montazeri-Gh and M. Asadi, "Intelligent approach for parallel HEV control strategy based on driving cycles," International Journal of Systems Science, vol. 42, no. 2, pp. 287-302, 2011.

[14] L. Glielmo, L. Iannelli, V. Vacca, and F. Vasca, "Gearshift control for automated manual transmissions," IEEE/ASME Transactions on Mechatronics, vol. 11, no. 1, pp. 17-26, 2006.

[15] M. Pettersson and L. Nielsen, "Gear shifting by engine control," IEEE Transactions on Control Systems Technology, vol. 8, no. 3, pp. 495-507, 2000.

[16] C. Chen and T. T. Liang, "Theoretic study of efficiency of twoDOFs of epicyclic gear transmission via virtual power," Journal of Mechanical Design, Transactions of the ASME, vol. 133, no. 3, Article ID 031007, 2011. 
[17] J. R. G. Ayats, J. V. Calvet, J. M. Canela, U. Diego-Ayala, and F. F. Artes, "Power transmitted through a particular branch in mechanisms comprising planetary gear trains and other fixed or variable transmissions," Mechanism and Machine Theory, vol. 46, no. 11, pp. 1744-1754, 2011.

[18] B. Mashadi, A. Kazemkhani, and R. Baghaei Lakeh, "An automatic gear-shifting strategy for manual transmissions," Proceedings of the Institution of Mechanical Engineers I, vol. 221, no. 5, pp. 757-768, 2007.

[19] S. E. Moon, H. S. Kim, and S. H. Hwang, "Development of automatic clutch actuator for automated manual transmissions," International Journal of Automotive Technology, vol. 6, no. 5, pp. 461-466, 2005.

[20] E. Galvagno, M. Velardocchia, and A. Vigliani, "Dynamic and kinematic model of a dual clutch transmission," Mechanism and Machine Theory, vol. 46, no. 6, pp. 794-805, 2011.

[21] M. Kulkarni, T. Shim, and Y. Zhang, "Shift dynamics and control of dual-clutch transmissions," Mechanism and Machine Theory, vol. 42, no. 2, pp. 168-182, 2007. 


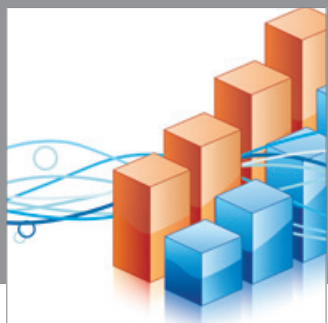

Advances in

Operations Research

mansans

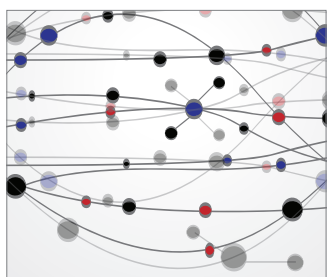

The Scientific World Journal
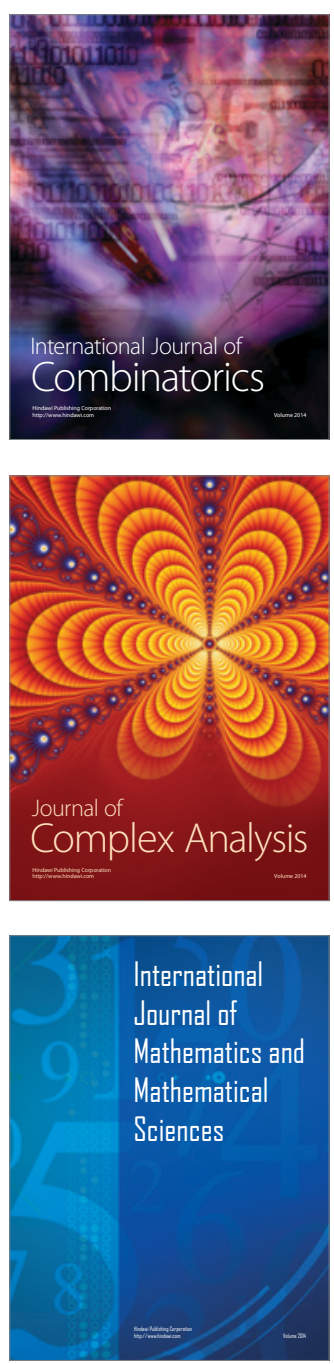
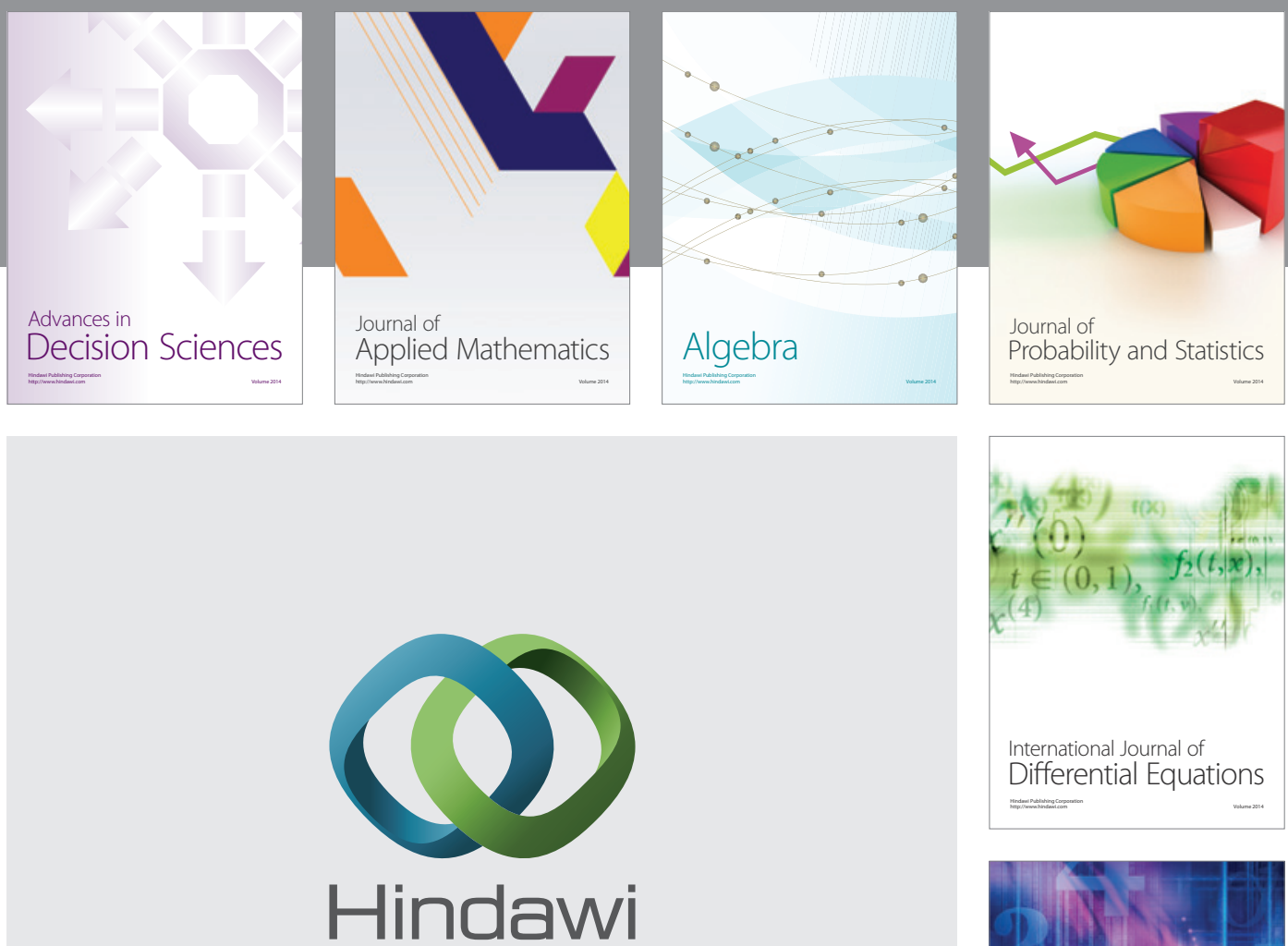

Submit your manuscripts at http://www.hindawi.com
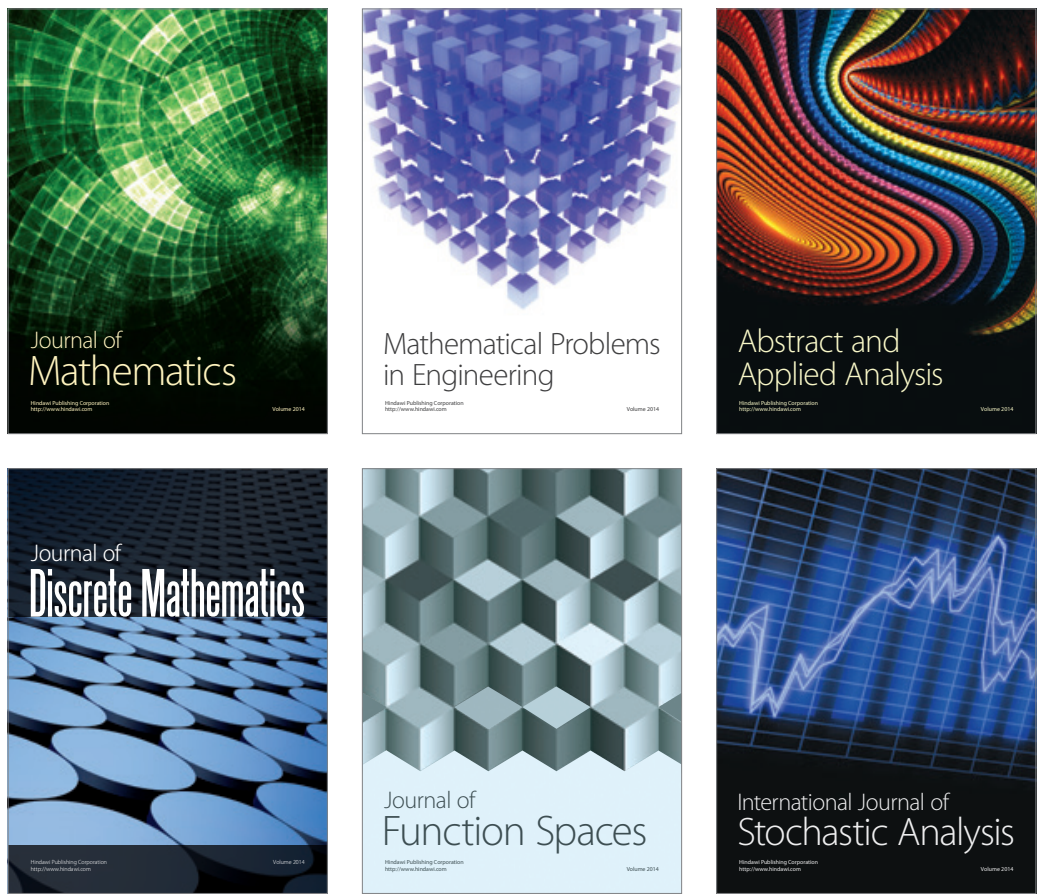

Journal of

Function Spaces

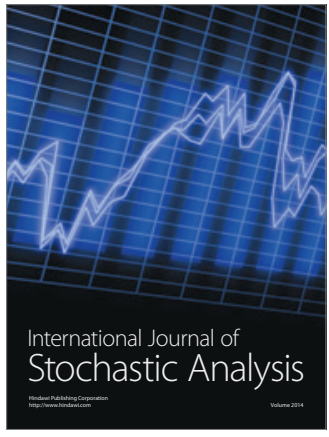

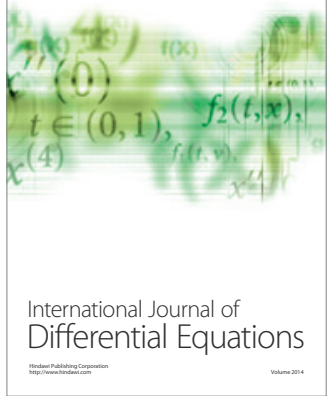
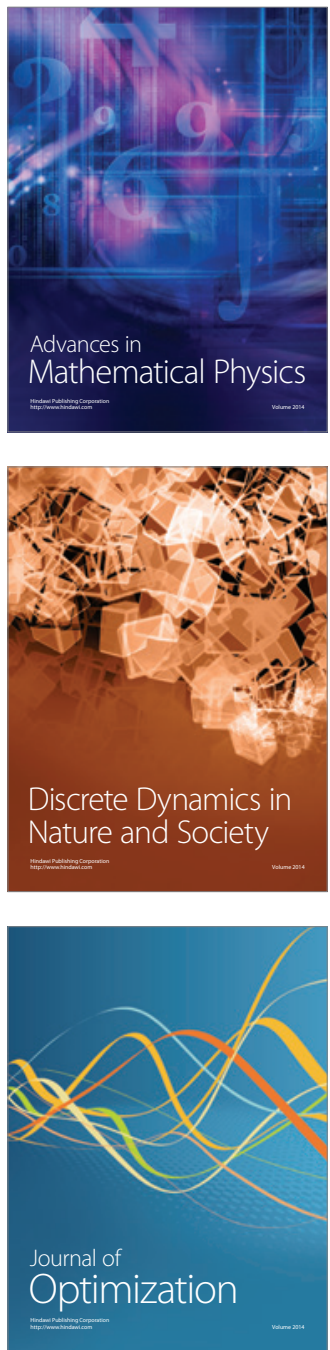